\title{
Influence of climate variability on whitefish (Coregonus lavaretus) year-class strength in a deep, warm monomictic lake
}

\author{
Dietmar Straile · Reiner Eckmann · Tobias Jüngling • \\ Gregor Thomas · Herbert Löffler
}

\begin{abstract}
The year-class strength (YCS) of Blaufelchen (Coregonus lavaretus) in deep Upper Lake Constance was analysed for a 52-year period, from 1947 to 1998. Despite strong anthropogenic influences on the species' population dynamics due to cultural eutrophication and oligotrophication, intense fishing, and large-scale stocking, the influence of climate variability associated with the North Atlantic Oscillation (NAO) is apparent in the data set. This influence is significant although large-scale stocking of cold-bred larvae was performed to avoid a mismatch of larvae with their food. The importance of stocking on YCS, however, is unclear and was only detectable when analysing a subset of the data. In addition to climate variability a yet unidentified factor related to zooplankton suitability as food for fish larvae, and density-dependent mortality probably related to cannibalism do significantly influence YCS. The NAO seemed to influence YCS twofold, through temperature effects on egg development time and on larval growth rate. The first of these two mechanisms is related to the NAO via a time lag of 1 year due to the specific mixing dynamics of warm monomictic Lake Constance. Hence, a warm
\end{abstract}

Communicated by Ulrich Sommer.

D. Straile $(\bowtie) \cdot R$. Eckmann · G. Thomas

Limnological Institute, University of Konstanz,

78464 Konstanz, Germany

e-mail: Dietmar.Straile@uni-konstanz.de

T. Jüngling · H. Löffler

Institut für Seenforschung, Langenargen

88085, Germany winter in the year before spawning results in earlier hatching of larvae, that is, hatching is decoupled from the actual meteorological conditions. This should make the larvae very prone to mismatch the dynamics of their food. However, we found no evidence for such a mismatch in this 52-year data set.

Keywords North Atlantic Oscillation - Egg mortality · Match-mismatch · Time-lagged effects · Stocking

\section{Introduction}

Long-term changes in the size of fish populations or in fish harvests provide classic examples for climate-driven fluctuations of animal populations (Cushing 1982; Alheit and Hagen 1997; Drinkwater et al. 2003; Ottersen et al. 2004). Climate variability and, e.g. recruitment of fish populations, may be linked via a large number of mechanisms (Ottersen et al. 2004) including water temperature effects on fish larvae growth (Eckmann et al. 1988; Ottersen and Loeng 2000; Schindler et al. 2005), effects of mixing on encounter rates between fish larvae and prey (Sundby et al. 1994), horizontal transport of larvae (Köster et al. 2001) and temporal synchronisation, i.e. match or mismatch between larval feeding and prey abundance (Cushing 1969, 1990). Especially, the synchronization of predator-prey dynamics is thought to be disrupted by global warming in aquatic (Edwards and Richardson 2004), but also in terrestrial ecosystems (Dewar and Watt 1992; Visser et al. 1998; Visser and Both 2005).

The pelagic spawning whitefish of Lake Constance, Coregonus lavaretus (local name: Blaufelchen) can be 
considered especially vulnerable to a potential disruption of its dynamics with its prey due to its specific biology and the mixing regime of the lake. The Blaufelchen of Lake Constance is the only known coregonid population performing pelagic spawning (Eckmann and Rösch 1998). The fish aggregate in the central part of Upper Lake Constance where spawning takes place within a short period of 35 days in late November/early December. Eggs sink to the lake bottom at approximately $1 \mathrm{~m} \mathrm{~min}^{-1}$. Most eggs are found at depths $\geq 200 \mathrm{~m}$. (Braum and Quo $\beta$ 1981), where they develop depending on water temperatures (Eckmann 1987) within approximately 2 months (Eckmann and Rösch 1998). After hatching, which takes place around February, larvae ascend to the surface within 1-2 days and stay in the littoral or in the upper water layers of the pelagic zone. Spring growth of larvae has been shown to be strongly temperature controlled (Eckmann and Pusch 1989). Warmer springs will lead to faster growth of larvae. As predatory mortality of fish larvae is strongly size dependent, warmer springs should result in lower predation losses, and hence higher year-class strength (YCS) (Miller et al. 1988; Bailey and Houde 1989). This hypothesis was supported by an analysis of whitefish YCS in 1962-1982 which showed that spring meteorological conditions did best predict YCS (Eckmann et al. 1988).

Upper Lake Constance is a warm monomictic lake with a mixing period in February/March. Winter meteorological conditions determine the lake's cooling during winter, the strength of mixing and consequently the deep-water temperatures of the lake (Straile et al. 2003). After the onset of stratification around April, hypolimnetic water layers are separated from further meteorological forcing until the next mixing period. Hence, deep-water temperatures prevailing during whitefish egg development in December/January are mostly determined by the meteorological conditions of the previous winter. However, after hatching and ascent to the surface, larvae are exposed to the actual winter and spring meteorological conditions. That is, with emergence from the lake bottom larvae can be considered to travel from the previous to the actual winter. This time travel after hatching may result in a mismatch between the larvae and their prey, especially when a warm winter (resulting in early hatching) is followed by a cold winter and early spring (resulting in a delayed spring bloom). In this study we analyse the effect of meteorological forcing on Blaufelchen YCS in the light of the lake's complex hydrodynamics.

\section{Materials and methods}

Study site

Upper Lake Constance is a large $\left(472 \mathrm{~km}^{2}\right)$ and deep $\left(z_{\max }=254 \mathrm{~m}\right)$ perialpine lake at the frontier between Austria, Germany, and Switzerland. During the study period, Lake Constance experienced eutrophication and oligotrophication with total phosphorus concentrations increasing from $<10 \mu \mathrm{g} \mathrm{l}^{-1}$ in the 1950s to almost $90 \mu \mathrm{g} \mathrm{l}^{-1}$ in the late $1970 \mathrm{~s}$ and decreasing again down to $<10 \mu \mathrm{g} \mathrm{l}^{-1}$ in recent years (Fig. 1). The consequences for the lake's ecology have been studied intensively (Walz et al. 1987; Straile and Geller 1998; Eckmann and Rösch 1998; Gaedke 1998; Bäuerle and Gaedke 1998), and the growth of whitefish, but not its YCS was affected (Eckmann et al. 1988; Eckmann and Rösch 1998). The whitefish population in Lake Constance is additionally strongly influenced by humans. Fishing has taken place since mediaeval times, and even stocking has been performed for more than a century (Grim 1983). During the study period stocking of larvae increased strongly in recent years (Fig. 1). More recently, climate variability associated with the North
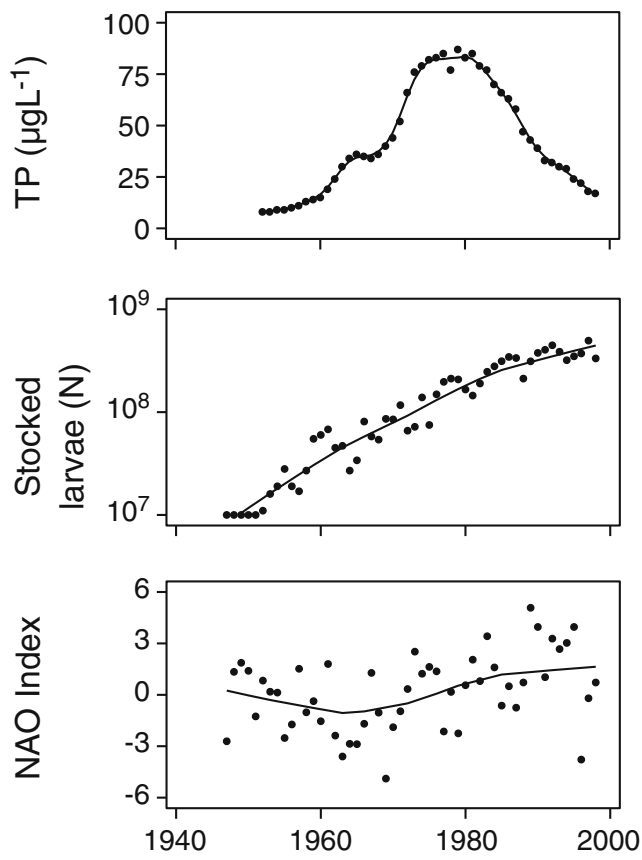

Fig. 1 Long-term development of environmental variables suggested to be important for whitefish year-class strength (YCS). Total phosphorus (TP) concentrations during winter mixing; the number of stocked larvae; and the index of the North Atlantic Oscillation $(N A O)$. All trend lines were computed using a LOESS fit 
Atlantic Oscillation (NAO) (Fig. 1; Hurrell 1995) has been shown to influence e.g. the strength of winter mixing, spring nutrient concentrations, temperatures (Straile et al. 2003), and Daphnia population dynamics during spring (Straile 2000). The spatiotemporal extent of the NAO-temperature relationship in warm monomictic Lake Constance is complex. The NAO was related significantly to water temperatures at all depths during the mixing period (February, March), to surface water temperatures in spring (until May), and to bottom water temperatures until the next mixing period, i.e. until February of the following year (Straile et al. 2003). That is, because of the large depth and warm monomictic character of the lake, deepwater temperatures during a specific winter are not related to the actual NAO, but to the NAO from the previous year, i.e. there is a time lag of 1 year. As a consequence, the incubation temperature of whitefish eggs in December and January is not determined by the actual NAO, but by the NAO of the previous year.

Lake Constance fishermen have reported monthly catches of Blaufelchen from Upper Lake Constance since 1914. In addition regular catches are performed by the Institut für Seenforschung and the Fischereiforschungsstelle des Landes Baden-Württemberg in Langenargen/Germany in order to provide an estimate of the age composition of the fish in each month. Combining this information allows calculation of the number of fish of a certain age class which is harvested from the lake in each month. Summing the catches of a distinct cohort across months gives an estimate of the virtual YCS of this cohort. The 1998 cohort is actually the last one that is fished completely. Hence, 1998 is the most recent year considered in this study. Virtual population analysis also allows us to estimate the numbers of Blaufelchen of age- 1 and older present in the lake during spawning. Using these numbers we test for the effect of density dependence (DD) on YCS.

The number of stocked larvae is recorded every year. A small percentage of larvae is pre-fed with lake zooplankton in the hatcheries before stocking. During 6 years (1983-1985, 1990, 1991 and 1995) within our study period, feeding larvae with zooplankton sampled in the lake resulted in histological damage and massive losses, whereas using Artemia nauplii as a food did not increase mortality (Eckmann and Rösch 1998). This suggests that the lake's zooplankton during these years was in some form unsuitable for the fish larvae. While several factors could be excluded as a cause for mortality (toxicity due to heavy metals or pesticides, virus or bacterial infections, parasites; Eckmann et al. 1986), it is still not known why the zooplankton was unsuitable in these years. However, analysis of the RNA/DNA ratios of larvae caught in the lake suggest that the problem of "unsuitable zooplankton" (Eckmann and Rösch 1998) is not restricted to the hatcheries. Hence, in our statistical analysis we include a categorical variable "unsuitable zooplankton" (UZ).

Egg abundances on the sediment were estimated from dredge samples on 11 sampling dates during the winter 2000/2001. Eggs were sampled with a conical net (50 $\times 30-\mathrm{cm}^{2}$ opening, 2-mm-mesh width) mounted on a sledge (Elster 1933). On each sampling date, the sledge was towed along five transects at depths between 170 and $254 \mathrm{~m}$ (Jüngling 2001). The area sampled per transect varied between 70 and $140 \mathrm{~m}^{2}$. Eggs were analysed microscopically and classified into five categories: healthy, unfertilised, dead, infected with fungi, and empty egg shells. For this study we consider only the number of healthy eggs.

The egg dynamics on the sediment was modelled with an individual-based model which has the following components: eggs were spawned on the 6th of December (median day of spawning in this winter) \pm 2 days SD, and will be found at the same day at the bottom of the sediment. From then on each egg has a daily probability of survival. For all eggs, survival was recorded and their accumulated degree-days (number of days survived $\times$ temperature at $200 \mathrm{~m}$ depth) were calculated. Hatching occurred when an egg reached $330 \pm 2$ degree-days (Eckmann 1987). The model was fit to the data by adjusting the total number of eggs spawned and the daily survival rate.

Total phosphorus concentrations were measured monthly during the study period (Rossknecht 1998). We used the total phosphorus concentration during winter (February, March) mixing (TP) as a proxy variable for the trophic status of the lake in a specific year. The index of the NAO (NAO-I) was used as a measure of climate variability and was obtained from the National Center for Atmospheric Research Climate Analysis Section home page (http://www.cgd. ucar.edu:80/cas/catalog/climind/) (Hurrell 1995). We used the winter index (average value from December to March) of the NAO in all analyses. We expect the NAO to influence YCS via its effect on water temperatures (Straile et al. 2003). Hence, water temperatures should also be related to YCS. Water temperatures were measured monthly at the central part of the lake at distinct depths, but only from 1962 onwards (Straile et al. 2003). To better compare the statistical relationships between YCS and water temperatures with those between YCS and NAO indices, we computed the latter ones also for the reduced time period from 1962 to 1998 . This can be considered also 
as a test of the robustness of the results. Within this shorter time series we test also for the effects of DD and trophic changes (TP) as these two variables were not available for the whole study period. YCS, the number of stocked larvae (S), as well as the numbers of large Blaufelchen (DD) were log-transformed prior to analyses. Models were compared using Akaike's Information Criterion (AIC). AIC rewards better model fit while penalizing for the number of parameters. Smaller AIC values indicate better models (Burnham and Anderson 1998). Data analysis was performed using SAS (SAS Institute 1988).

\section{Results and discussion}

Whitefish YCS declined from the mid-1950s to a low in the mid-1960s and since then increased towards recent years (Fig. 2). Considering the years from 1947 to 1998 YCS did not show any significant trend $(r=0.05$, n.s.). YCS in UZ years was significantly lower than in normal years $\left(n=52, r^{2}=0.17, P<0.005\right)$. This suggests that zooplankton unsuitability was not only a problem in the hatcheries, but resulted also in larval mortality in situ, thereby resulting into a lower YCS. Besides UZ no environmental factor is significantly related to YCS on its own. The best two-factor model according to AIC is with the lagged NAO-I $\left(\mathrm{NAO}_{-1}-\mathrm{I}\right)$ and UZ, explaining $32 \%$ of the variability in YCS (Table 1; Fig. 3). Variability in $\mathrm{NAO}_{-1}-\mathrm{I}$ did explain variability in YCS in both normal and UZ years. In addition to $\mathrm{NAO}_{-1}-\mathrm{I}$, also the NAO-I, but not the number of stocked larvae contributed significantly to YCS when the effect of UZ was also considered. The best model included UZ, and bothe the $\mathrm{NAO}_{-1}$ and the NAO indices (Table 1)

$$
\begin{aligned}
\mathrm{YCS}= & 2.98-0.9 \times \mathrm{UZ}+0.08 \\
& \times \mathrm{NAO}_{-1}-\mathrm{I}+0.05 \times \mathrm{NAO}-\mathrm{I}
\end{aligned}
$$

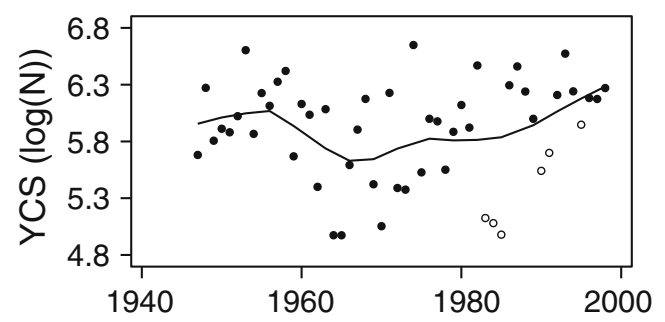

Fig. 2 Long-term development of whitefish YCS. The trend line is given by a LOESS fit. Open circles indicate years with unsuitable zooplankton (UZ)
Using the shorter time scale, i.e. 1962-1998, UZ and the number of stocked larvae alone were significantly related to YCS. However, all other factors contributed significantly to explain YCS variability when UZ was considered. The best model according to AIC explained $70 \%$ of the variability in YCS and included UZ, $\mathrm{NAO}_{-1}-\mathrm{I}$, the number of stocked larvae, and the Blaufelchen stock during spawning (DD), but not TP and the NAO-I (Table 1)

$$
\begin{aligned}
\mathrm{YCS}= & 0.89-0.93 \times \mathrm{UZ}+1.1 \times \mathrm{S}+0.07 \\
& \times \mathrm{NAO}_{-1}-\mathrm{I}-0.2 \times \mathrm{DD}
\end{aligned}
$$

During the shorter time period the number of stocked larvae was the best predictor of YCS when considering UZ (Table 1). Both, YCS and the number of stocked larvae increased from the early 1960s onward. However, high levels of stocking did not prevent strong fluctuations in YCS during the last 20 years. Furthermore, YCS was high for the first 10 years of the study period when stocking was still low. Consequently, stocking was not successful in explaining YCS when considering the period 1947-1998. This shows that strong year classes were formed without the high levels of stocking that occurred during recent years. However, it does not exclude the possibility that stocking helped to prevent low YCS in the most eutrophic years, i.e. the 1970 s, when $\mathrm{O}_{2}$ concentrations at the bottom were low (Straile et al. 2003) and may have reduced survival of whitefish eggs. In contrast to the number of stocked larvae, the NAO and more strongly the $\mathrm{NAO}_{-1}$ indices did contribute significantly to YCS during the entire but also during the shorter time period. For the latter time period the number of Blaufelchen present in the lake at the time of spawning also contributed significantly to the model whereby a higher number of whitefish resulted in a lower YCS. This was already observed by Eckmann et al. (1988) and attributed either to competitive interactions or to adult cannibalism on larvae. Especially the latter mechanism is regarded to be an important densitydependent regulator of YCS in fish populations (Bailey and Houde 1989).

The relationship between YCS and water temperatures was analysed while controlling for the effects of $\mathrm{UZ}$, i.e. using $\mathrm{UZ}$ as a partial variable in correlation analyses. As water temperatures in different depths and months were strongly inter-related, YCS was strongly related to water temperatures during different months and depths (Fig. 4). Highest correlation coefficients were observed between YCS and deep-water temperatures during winter, i.e. during egg develop- 
Table 1 Regression models relating year-class strength (YCS) to the environmental variables $\mathrm{NAO}$ index $(N A O-I)$, the lagged NAO-I $\left(N_{A} O_{-1}-I\right)$, presence of unsuitable zooplankton $(U Z)$, the number of stocked larvae $(S)$, number of adult whitefish during spawning $(D D)^{\mathrm{a}}$ and the total phosphorus concentration during winter mixing $(T P)^{\mathrm{a}}$. For all models Akaike's information criterion $(A I C)$ is computed to compare model performance. Smaller values of AIC indicate more parsimonious and better models

\begin{tabular}{|c|c|c|c|}
\hline Variables & $n$ & $R^{2}$ & $\mathrm{AIC}$ \\
\hline \multicolumn{4}{|l|}{ Complete time series (1947-1998) } \\
\hline NAO-I & 52 & 0.026 & 65.8 \\
\hline $\mathrm{NAO}_{-1}-\mathrm{I}$ & 52 & 0.026 & 65.8 \\
\hline $\mathrm{UZ}(* * *)$ & 52 & 0.17 & 57.6 \\
\hline $\mathrm{S}$ & 52 & 0 & 67 \\
\hline UZ $(* * *)$ NAO-I $(*)$ & 52 & 0.27 & 53 \\
\hline $\mathrm{UZ}(* * * *) \mathrm{NAO}_{-1}-\mathrm{I}(* * *)$ & 52 & 0.32 & 48.7 \\
\hline $\mathrm{UZ}(* * * *) \mathrm{S}$ & 52 & 0.21 & 56.8 \\
\hline UZ $(* * * * *)$ NAO $_{-1}-\mathrm{I}(* *)$ NAO-I $(P<0.06)$ & 52 & 0.37 & 46.8 \\
\hline $\mathrm{UZ}(* * * * *) \mathrm{NAO}_{-1}-\mathrm{I}(* *)$ NAO-I S & 52 & 0.38 & 47.7 \\
\hline \multicolumn{4}{|l|}{ Reduced time series (1962-1998) } \\
\hline NAO-I & 37 & 0.04 & 53.6 \\
\hline $\mathrm{NAO}_{-1}-\mathrm{I}$ & 37 & 0.05 & 53.1 \\
\hline $\mathrm{UZ}(*)$ & 37 & 0.16 & 48.8 \\
\hline $\mathrm{S}(* *)$ & 37 & 0.18 & 47.7 \\
\hline $\mathrm{TP}$ & 37 & 0 & 54.9 \\
\hline DD & 37 & 0 & 55.1 \\
\hline $\mathrm{UZ}(* * *)$ NAO-I $(*)$ & 37 & 0.29 & 44.4 \\
\hline $\mathrm{UZ}(* * * * *) \mathrm{NAO}_{-1}-\mathrm{I}(* * *)$ & 37 & 0.40 & 38.2 \\
\hline $\mathrm{UZ}(* * * * *) \mathrm{S}(* * * * *)$ & 37 & 0.54 & 27.7 \\
\hline $\mathrm{UZ}(*) \mathrm{TP}$ & 37 & 0.16 & 50.6 \\
\hline $\mathrm{UZ}(* *) \mathrm{DD}(* * * * *)$ & 37 & 0.18 & 49.5 \\
\hline $\mathrm{UZ}(* * * * *) \mathrm{S}(* * * * *)$ NAO-I & 37 & 0.56 & 28. \\
\hline $\mathrm{UZ}(* * * * *) \mathrm{S}(* * * * *) \mathrm{TP}(*)$ & 37 & 0.55 & 29. \\
\hline $\mathrm{UZ}(* * * * *) \mathrm{S}(* * * * *) \mathrm{NAO}_{-1}-\mathrm{I}(*)$ & 37 & 0.62 & 23. \\
\hline $\mathrm{UZ}(* * * * *) \mathrm{S}(* * * * *) \mathrm{DD}(*)$ & 37 & 0.63 & 22.4 \\
\hline $\mathbf{U Z}(* * * * *) \mathbf{S}(* * * * *) \mathbf{N A O}-\mathrm{I}(* *) \mathbf{D D}(* *)$ & 37 & 0.7 & 16.1 \\
\hline $\begin{array}{l}\mathrm{UZ}(* * * * *) \mathrm{S}(* * * * *) \mathrm{NAO}_{-1}-\mathrm{I}(*) \text { NAO-I DD } \\
(* * *) \mathrm{TP}\end{array}$ & 37 & 0.73 & 17.1 \\
\hline
\end{tabular}

$* P<0.05$, ** $P<0.01, * * * P<0.005, * * * * P<0.001, * * * * P<$ 0.0001 (significance levels for the individual variables)

a DD and TP were not available for the time series from 1947 to 1998, and hence were only considered for the period from 1962 to 1998

ment at the bottom. This would be expected if the lagged NAO exerts a significant influence on YCS, i.e. if the duration of embryogenesis is important for YCS. Correlations with surface temperatures were also high during spring, i.e. during the larval phase of whitefish. A significant relationship between April temperatures and YCS had also been observed by Eckmann et al. (1988) who suggested that the temperature influence on growth rate affects larval survival and finally YCS. But upper water column temperatures of the winter preceding spawning were also significantly related to YCS. This is due to the fact that during this time mixing takes place and the deep-water temperature is determined (Straile et al. 2003). These correlations

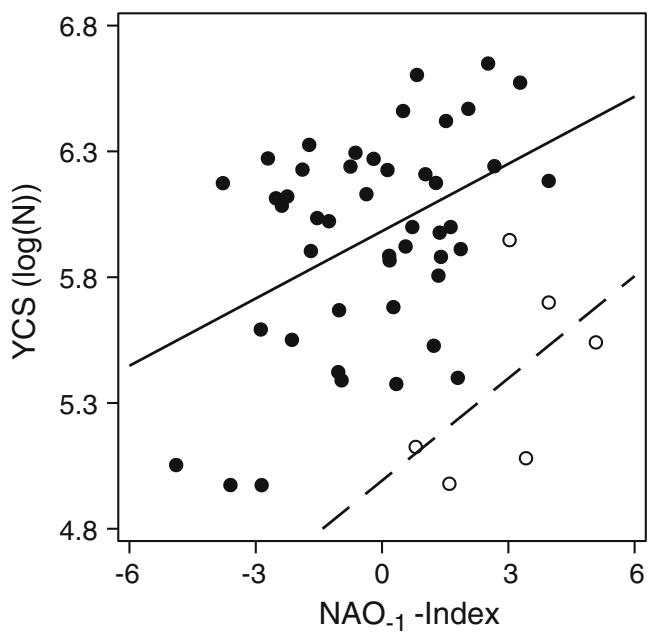

Fig. 3 Relationship between Blaufelchen YCS and the NAO index lagged 1 year $\left(N A O_{-1}\right.$ Index $)$. Open circles represent years with UZ. For abbreviations, see Figs. 1 and 2

again support the link between YCS and the NAO of the previous year.

Hence, the present regression analyses largely confirmed the results regarding the effects of spring meteorology, stocking and DD observed for the time period from 1962 to 1981 (Eckmann et al. 1988). However, Eckmann et al. (1988) did not analyse a possible effect of deep-water temperature variability on YCS as they considered deep-water temperatures to be constant (Eckmann and Rösch 1998). But, deepwater temperatures were not constant, instead they varied during the study period by $>1{ }^{\circ} \mathrm{C}$ (Straile et al. 2003), and consequently may have ecological effects.

When considering the influence of climate variability on YCS, it should be kept in mind that stocking at least in recent years was intense. While the NAO, i.e. spring surface temperatures, might influence both naturally recruited and stocked larvae, the lagged effect of the NAO via bottom temperatures cannot act on stocked larvae. Therefore, with the increasing importance of larval stocking for YCS, i.e. with an increasing contribution of stocked larvae to YCS, the importance of lagged NAO should decrease as stocked larvae never experienced deep-water temperatures. Hence, larval stocking and its possible influence on YCS needs to be discussed thoroughly.

Larval stocking has been performed at Lake Constance for more than a century (Grim 1983). During the study period the number of larvae stocked per year increased approximately 40-fold. In addition, hatcheries around the lake switched from incubation of eggs at $4^{\circ} \mathrm{C}$ to cold incubation at around $1^{\circ} \mathrm{C}$ during the $1980 \mathrm{~s}$. While before cold incubation was implemented, the 

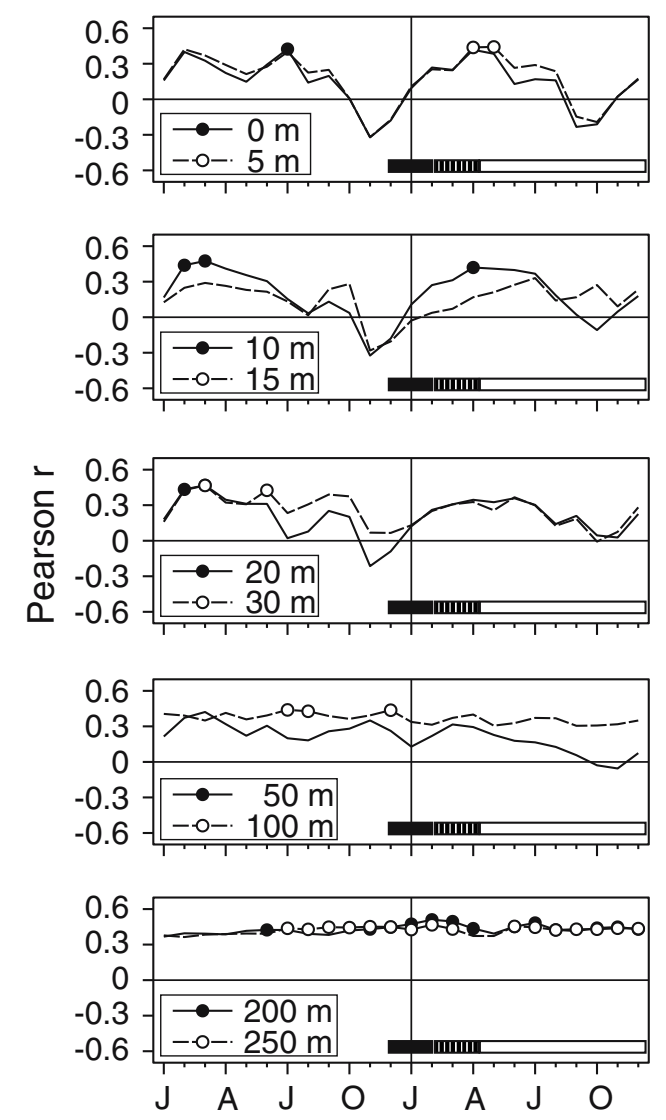

Fig. 4 Partial Pearson correlation coefficients between the YCS and water temperatures measured at different months and depths in Lake Constance when controlling for the effect of larval mortality. Symbols indicate correlation coefficients with $P<0.01$. Bars show the timing and duration of egg (black), larval (hatched) and juvenile (white) periods

lake was stocked with larvae at approximately the same time when larvae hatched in situ, with cold incubation, larvae are stocked up to 2 months after hatching occurs in situ. The main argument for cold incubation is that later stocking improves the match between the larvae and their plankton food. However, these efforts neither increased YCS significantly, nor did they prevent strong variability in YCS during the study period. Several studies tried to analyse the success of the stocking programme and estimated that 17\% (Nümann 1967), 53\% (Hartmann and Brenner 1983), 72\% (Hartmann and Quo $\beta$ 1989) of whitefish larvae in the lake derived from stocking. A recent study analysing the recaptures of Alizarin-stained larvae suggested that stocked larvae contributed approximately $60 \%$ to the abundance of age- 0 fish caught in autumn 2003 (Eckmann et al. 2006). While, the relative success of larvae from the lake versus those from hatcheries likely varies from year to year, these numbers suggest that at least in some years a considerable percentage of YCS stems from the hatcheries. However, even if $60 \%$ originate from hatcheries, the remaining $40 \%$ of the YCS are produced in situ and the interannual variability in survival of these fish might be influenced by interannual variability in deepwater temperatures.

A hidden assumption of cold incubation is that whitefish are maladapted to their environment, that is, larval hatching mismatches plankton succession. Clearly, evolution is not expected to result in perfect adaptation; however, it is hard to see why selection would not, e.g. result in later spawning of whitefish, if larvae do predictably hatch too early. However, if we assume that the time of hatching in situ is not a maladaptation, this might imply that delayed hatching reduces survival probabilities of stocked larvae. At least during years with an early start of stratification, in situ hatched larvae might have already increased in size when cold-bred larvae are stocked into the lake. Being larger is often considered to be an important survival advantage for fish larvae (Miller et al. 1988) and delayed hatching of larvae would be even more of a disadvantage if early hatching is an adaptation to avoid predators which will become more numerous as the season progresses. Also a calanoid copepod uses this niche of low predation during late winter/early spring successfully in Lake Constance: late winter offspring of Eudiaptomus do have much higher survival probabilities than offspring born during the rest of the year (Seebens et al., in review).

To deepen our understanding of the possible role of egg mortality for YCS, we analysed egg mortality in situ. The fate of whitefish eggs in the lake was examined in the winter 2000/2001. Spawning in this year took place around 6th of December. The first sampling was done on 12th of December and yielded an abundance of $18.3 \pm 2.4$ healthy eggs $\mathrm{m}^{-2}$ (Fig. 5). Egg density declined continuously towards the last sampling (2nd of March), when only $0.2 \pm 0.2$ healthy eggs $\mathrm{m}^{-2}$ were found. The data were reasonably fit with an egg mortality rate of $0.02 \mathrm{day}^{-1}$ and a total number of 20 spawned eggs $\mathrm{m}^{-2}$ when using a development time of 330 degree-days (Eckmann 1987). These rates suggest an overall egg mortality of $75 \%$ during the winter 2000/2001.

Mean winter deep-water temperatures at 200-m depth varied during the study period from 3.8 to $5.1^{\circ} \mathrm{C}$. Assuming hatching takes place after 330 degree-days (Eckmann 1987), this range in deep-water temperatures translates into egg developmental times between 65 and 87 days. Hence, deep-water warming during the recent decades (Straile et al. 2003) reduced egg developmental time by about 3 weeks. This has two 
implications: first, the period of potential egg mortality is shortened, and second, larvae appear earlier in the plankton.

Egg mortality due to predation has been considered a major loss for the Blaufelchen. Up to now, burbot and planarians have been identified to prey on whitefish eggs (Nümann and Quo $\beta$ 1972). The Lake Constance whitefish do have short egg development times compared to other whitefish species (Eckmann 1987) which has been interpreted as an adaptation to reduce egg mortality (Eckmann and Rösch 1998). Assuming a mortality rate of 0.02 day $^{-1}$ as in 2000/2001 and-all other things being equal-a decrease in developmental time from 87 to 65 days, the simulation model predicts an increase in total egg survival from 22 to $30 \%$. Hence, warming could increase the survival of naturally spawned whitefish eggs considerably.

On the other hand, high deep-water temperatures will result in hatching of larvae already in early February, definitely well before the onset of the phytoplankton bloom and the subsequent increase in zooplankton which may be delayed even until April in some years (Weisse et al. 1990; Gaedke et al. 1998; Straile 2000). Starvation resistance of Blaufelchen larvae is rather high and at the low temperatures after hatching larvae are able to starve for up to 50 days until the point of no return is reached (Eckmann and Pusch 1991). This would allow larvae hatched in February to wait until even a late onset of the phytoplankton bloom. However, several copepod species are present in the plankton also during winter and, e.g. the calanoid Eudiaptomus gracilis reproduces also during February (Seebens et al., in review), which will provide nauplii for whitefish larvae. Therefore, larvae present in the lake in February and March do have the chance to feed and may gain some advantage over cold-bred larvae in, e.g. an increased ability to capture evasive

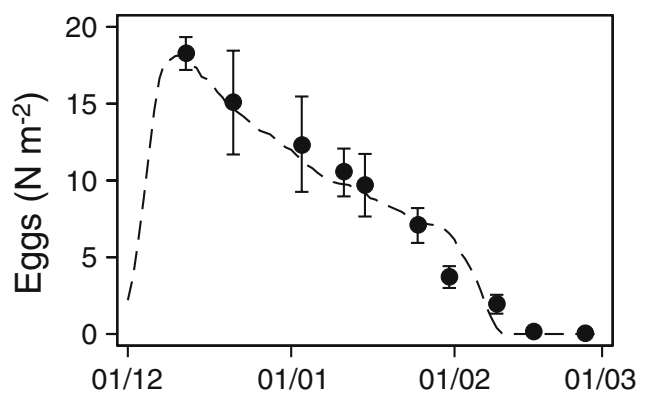

Fig. 5 Seasonal course of egg abundances in the winter 2000/ 2001 in the Blaufelchen spawning area at depths between 170 and $254 \mathrm{~m}$. Model results with a spawning density of 20 eggs $\mathrm{m}^{-2}$, a mortality rate of $2 \%$ per day and hatching after 330 degreedays are shown as a dotted line prey like copepods, earlier onset of growth and probably finally in survival (Miller et al. 1988). As a consequence, the YCS time series does not provide any evidence for a mismatch of whitefish larvae with their food despite the time travel of larvae after they emerge from the bottom. Winters with high bottom temperatures or a high $\mathrm{NAO}_{-1}$-I which were followed by low spring temperatures or a low NAO-I did not show reduced YCS. In contrast, highest YCS were observed in years with high $\mathrm{NAO}_{-1}$ and NAO indices

\section{Conclusions}

Climate variability associated with the NAO did influence YCS of Blaufelchen in Lake Constance. Our time series analyses suggest that the influence of the $\mathrm{NAO}$ on Blaufelchen ecology is twofold, i.e. affecting the growth of larvae during spring, and with a time lag of 1 year, the egg development time. The influence of climate variability can be detected in the time series despite the fact that the population dynamics are severely modified anthropogenically due to strong fishing pressure, intensive stocking, and changes in the trophic status of the lake. This suggests that with conditions unmodified by humans, the effects of climate variability on the YCS of this population may be very strong. However we are unsure about the relative importance of the two effects on YCS as water temperatures in the lake during different months and depths were strongly interrelated. Nevertheless, our results show that the warm monomictic stratification regime of Lake Constance (Straile et al. 2003) results in a 1-year time lag of an ecological response, i.e. the developmental time of fish eggs, to meteorological forcing. Our results do further suggest that for a better understanding of YCS the fate of naturally spawned eggs and of both naturally and artificially produced larvae should be studied more intensively.

Acknowledgements We thank Henno Rossknecht and Michael Kugler for providing data on water temperatures and whitefish YCS, and two anonymous reviewers for their valuable comments. This research was supported by the European Union Environment and Climate project CLIME (EVK1-CT-200200121) and the Deutsche Forschungsgemeinschaft within the priority program 1162 AQUASHIFT.

\section{References}

Alheit J, Hagen E (1997) Long-term climate forcing of European herring and sardine populations. Fish Oceanogr 6:130-139

Bailey KM, Houde ED (1989) Predation on eggs and larvae of marine fishes and the recruitment problem. Adv Mar Biol 25:1-83 
Bäuerle E, Gaedke U (1998) Lake Constance-characterization of an ecosystem in transition. Arch Hydrobiol Spec Iss Adv Limnol 53:1-610

Braum E, Quo $\beta$ H (1981) Beobachtungen über die Entwicklung des Blaufelchens (Coregonus lavaretus wartmanni) im Bodensee-Obersee. Schweiz Z Hydrobiol 43:114-125

Burnham KP, Anderson DR (1998) Model selection and inference-a practical information-theoretic approach. Springer, Berlin Heidelberg New York

Cushing DH (1969) The regularity of the spawning season of some fishes. J Cons Int Explor Mer 185:201-213

Cushing DH (1982) Climate and fisheries. Academic Press, London

Cushing DH (1990) Plankton production and year-class strength in fish populations: an update of the match/mismatch hypotheses. Adv Mar Biol 26:249-293

Dewar RC, Watt AD (1992) Predicted changes in the synchrony of larval emergence and budburst under climatic warming. Oecologia 89:557-559

Drinkwater KF, Belgrano A, Borja A, Conversi A, Edwards M, Greene CH, Ottersen G, Pershing AJ, Walker H (2003) The response of marine ecosystems to climate variability associated with the North Atlantic Oscillation. In: Hurrell JW, Kushnir Y, Ottersen G, Visbeck M (eds) The North Atlantic Oscillation, pp 211-234

Eckmann R (1987) A comparative study on the temperature dependence of embryogenesis in three coregonids (Coregonus spp.) from Lake Constance. Schweiz Z Hydrobiol 49:353-362

Eckmann R, Pusch M (1989) The influence of temperature on growth of young coregonids (Coregonus lavaretus L.) in a large prealpine lake. Rapp P-V Reun Conserv Explor Mer 191:201-208

Eckmann R, Pusch M (1991) At what life stage is year-class strength of coregonids (Coregonus lavaretus L.) in Lake Constance determined? Verh. Int Verein Limnol 24:24652469

Eckmann R, Rösch R (1998) Lake Constance fisheries and fish ecology. Arch Hydrobiol Spec Iss Adv Limnol 53:285-301

Eckmann R, Rösch R, Ortlepp J, Kleifeld G (1986) Survival and growth of coregonid larvae from Lake Constance fed on zooplankton of different origin. Arch Hydrobiol Suppl Ergebn Limnol 22:203-214

Eckmann R, Gaedke U, Wetzlar HJ (1988) Effects of climatic and density-dependent factors on year-class strength of Coregonus lavaretus in Lake Constance. Can J Fish Aquat Sci 45:1088-1093

Eckmann R, Kugler M, Ruhlé C (2006) Evaluating the success of large-scale whitefish stocking at Lake Constance. Arch Hydrobiol Beih Ergebn Limnol 60 (in press)

Edwards M, Richardson AJ (2004) Impact of climate change on marine pelagic phenology and trophic mismatch. Nature 430:881-884

Elster HJ (1933) Eine Schlitten-Dredge. Int Rev Ges Hydrobiol 29:290-292

Gaedke U (1998) Functional and taxonomical properties of the phytoplankton community of large and deep Lake Constance: interannual variability and response to re-oligotrophication (1979-1993). Arch Hydrobiol Spec Iss Adv Limnol 53:119-141

Gaedke U, Ollinger D, Bäuerle E, Straile D (1998) The impact of the interannual variability in hydrodynamic conditions on the plankton development in Lake Constance in spring and summer. Arch Hydrobiol Spec Iss Adv Limnol 53:565-585
Grim J (1983) Zur Geschichte der "künstlichen Erbrütung" von Blaufelchen. Schr V G Bodensee 101:131-147

Hartmann J, Brenner T (1983) Versuch zu Kosten/Nutzen der Felchenerbrütung am Beispiel des Bodensees. Öster Fisch 36:231-234

Hartmann J, Quo $\beta$ H (1989) Gedredgte Eier, Laicherbestand, Brutanstaltquote, Jahrgangserfolg im Bodensee. Oster Fisch 42:84-87

Hurrell JW (1995) Decadal trends in the North Atlantic Oscillation: regional temperatures and precipitation. Science 269:676-679

Jüngling TM (2001) Räumlich zeitliche Verteilung und Entwicklung der Felcheneier im Bodensee sowie experimentelle Untersuchung des Erbrütungserfolges in Abhängigkeit von verschiedenen Sedimenttypen. Diploma thesis, EberhardKarls-Universität Tübingen

Köster F, Hinrichsen HH, St John MA, Schnack D, MacKenzie BR, Tomkiewicz J, Plikshs M (2001) Developing Baltic cod recruitment models. II. Incorporation of environmental variability and species interaction. Can J Fish Aquat Sci 58:1534-1556

Miller TJ, Crowder LB, Rice JA, Marschall EA (1988) Larval size and recruitment mechanisms in fishes-toward a conceptual framework. Can J Fish Aquat Sci 45:1657-1670

Nümann W (1967) Ungewollte und gezielte Eingriffe in die Populationsdynamik der Blaufelchen. Arch Fischereiwissensch 18:12-24

Nümann W, Quo $\beta$ H (1972) Strudelwürmer dezimieren den Felchenlaich-Ursachen für die unterschiedlichen Fangerträge in der Blaufelchen-Fischerei des Bodensees. Fischwirt 22:25-27

Ottersen G, Loeng H (2000) Covariability in early growth and year-class strength of Barents Sea cod, haddock, and herring: the environmental link. ICES J Mar Sci 57:339-348

Ottersen G, Alheit J, Drinkwater KF, Friedland K, Hagen E, Stenseth NC (2004) The responses of fish populations to ocean climate fluctuations. In: Stenseth NC (ed) Ecological impacts of the North Atlantic Oscillation on North Atlantic ecosystems. Oxford University Press, Oxford, pp 73-94

Rossknecht H (1998) Langjährige Entwicklung chemischer Parameter im Bodensee-Obersee. Ber Int Gewässerschutzkomm Bodensee 48:1-137

SAS Institute (1988) SAS/STAT user's guide, release 6.03 edition. SAS Institute, Cary, N.C.

Schindler DE, Rogers DE, Scheuerell MD, Abrey CA (2005) Effects of changing climate on zooplankton and juvenile sockeye salmon growth in southwestern Alaska. Ecology 86:198-209

Straile D (2000) Meteorological forcing of plankton dynamics in a large and deep continental European lake. Oecologia 122:44-50

Straile D, Geller W (1998) Crustacean zooplankton in Lake Constance from 1920 to 1995: response to eutrophication and reoligotrophication. Arch Hydrobiol Spec Iss Adv Limnol 53:255-274

Straile D, Joehnk K, Rossknecht H (2003) Complex effects of winter warming on the physico-chemical characteristics of a deep lake. Limnol Oceanogr 48:1432-1438

Sundby S, Ellertsen B, Fossum P (1994) Encounter rates between first-feeding cod larvae and their prey during moderate to strong turbulent mixing. ICES J Mar Sci Symp 198:393-405

Visser ME, Both C (2005) Shifts in phenology due to global climate change: the need for a yardstick. Proc R Soc B Biol Sci 272:2561-2569 
Visser ME, van Nordwijk J, Tinbergen JM, Lessels CM (1998)

Warmer springs lead to mistimed reproduction in great tits (Parus major). Proc R Soc Lond B 265:1867-1870

Walz N, Elster HJ, Mezger M (1987) The development of the rotifer community structure in Lake Constance during its eutrophication. Arch Hydrobiol Suppl 74:452-487
Weisse T, Müller H, Pinto-Coelho RM, Schweizer A, Springmann D, Baldringer G (1990) Response of the microbial loop to the phytoplankton spring bloom in a large prealpine lake. Limnol Oceanogr 35:781-794 